\title{
Avaliação da promoção da aprendizagem em Educação a Distância através do uso de um Objeto de Aprendizagem
}

\author{
Raquel Fernandez, Sandro José Rigo \\ UNISINOS - Universidade do Vale do Rio dos Sinos \\ rfernandez@unisinos.br, rigo@unisinos.br
}

\begin{abstract}
Resumo: Este trabalho analisa aspectos de materiais instrucionais e sua utilização na Educação a Distância, avaliando o resultado da utilização de diferentes recursos digitais para fomentar processos de aprendizagem significativa. Partindo de um estudo de caso real onde se constatou dificuldade dos alunos, foi construído um objeto de aprendizagem com recursos multimídia sobre este conteúdo específico. Após a sua utilização pelos alunos, realizou-se um processo de avaliação e os resultados obtidos indicam que a ferramenta contribui para o desenvolvimento e para a promoção de um maior interesse no assunto e maiores facilidades no processo de aprendizagem pelos alunos.
\end{abstract}

Palavras-chave: Educação a distância. Objetos de aprendizagem.

\section{Evaluation of learning promoting in Distance Learning with the use of a Learning Object}

\begin{abstract}
This paper presents some aspects of the relationship between pedagogical theories and interactivity of distance education with the skills of teachers and tutors using different digital resources for learning purposes. From an analysis of interaction was built on a learning object content specific to multimedia character. After its use by students, this digital resource was subjected to an evaluation process and the results indicate that the tool contributes to both the development of skills of the tutor and to promote a dynamic and meaningful learning.
\end{abstract}

Keywords: Distance Education. Learning objects.

\section{INTRODUÇÃO}

No contexto educacional brasileiro envolvendo a modalidade de Educação a Distância (EAD) os educadores têm se deparado com a necessidade de alternativas pedagógicas que contribuam e auxiliem o processo de ensino e aprendizagem de forma cativo que motiva e desperta o interesse do aluno a explorar, a pesquisar, a descrever e a refletir sobre suas ideias. As constantes inovações tecnológicas levam as instituições de ensino a abrirem espaço para novas práticas pedagógicas utilizando, para tanto, instrumentais atraentes e interativos, que possibilitam aos alunos a colaboração, experimentação e a associação dos conteúdos com as situações reais do cotidiano.

Este tipo de material didático digital é conhecido como objeto educacional ou objeto de aprendizagem. De forma ampla, um objeto de aprendizagem pode ser considerado como qualquer material educacional que visa apoiar o processo de ensinoaprendizagem baseado em mediação digital, visando a reusabilidade (WILEY, 2000). O suporte ao texto por meio de ilustrações, gráficos, ícones, animações, jogos, entre outros e também a utilização de uma linguagem que procura estabelecer um diálogo com os 
alunos, são elementos que privilegiam os diversos perfis cognitivos existentes, podendo levar a um aumento da capacidade de reflexão e produção de conhecimento do aluno.

Os objetos de aprendizagem ou educacionais podem ser vistos como valiosos recursos no processo de ensino e aprendizagem. Tais podem e devem ser analisados, melhorados e revisados por meio de avaliações. A qualidade de um objeto de aprendizagem pode ser aprimorada em decorrência de avaliações ao longo do projeto e também após a sua aplicação. As avaliações dos objetos de aprendizagem são, ainda, importantes para construir e apoiar comunidades e equipes voltadas a aprender a trabalhar com os objetos, além de auxiliar na criação de padrões de avaliação que possam direcionar essa prática. Isto também implica no desenvolvimento das competências e novos saberes por parte dos docentes, principalmente daqueles que atuam diretamente com os alunos, como é o caso dos professores tutores da EAD.

Dada a diversidade dos recursos digitais existentes, como distinguir quais instrumentos possibilitam uma melhor aprendizagem? Qual a percepção dos alunos sobre este tipo de recurso ou ferramenta? Contextualizado a partir destes questionamentos, o objeto de estudo deste artigo é a construção, aplicação e avaliação de melhorias propiciadas pelo uso de um objeto de aprendizagem de determinado conteúdo curricular específico. $\mathrm{O}$ objetivo geral é verificar, por meio de avaliações, se o objeto de aprendizagem aplicado com uma amostra de alunos resultou em ganhos no processo de ensino e aprendizagem. De forma a contemplar o problema de pesquisa e seus objetivos, a metodologia utilizada envolve a revisão bibliográfica sobre a temática, passando posteriormente a aplicação e análise de um estudo de caso. Tal estudo foi aplicado com os alunos dos cursos de graduação em cursos de Educação a Distância em Administração e Ciências Contábeis da Universidade do Vale do Rio dos Sinos (UNISINOS). Para a avaliação do objeto de aprendizagem a metodologia empregada é a aplicação de questionário preenchido pelos alunos da amostra e, posteriormente, a análise de seus resultados. Além deste questionário, são realizadas análises envolvendo outros instrumentos complementares, que possibilitam identificar impactos positivos associados ao uso do objeto de aprendizagem utilizado.

Este trabalho, portanto, analisa aspectos ligados aos materiais instrucionais e sua utilização na Educação a Distância, buscando avaliar o resultado da utilização de diferentes recursos digitais para fomentar processos de aprendizagem significativa. Partindo de um estudo de caso real onde constatou-se dificuldade dos alunos para o conteúdo de Elasticidade, foi construído um objeto de aprendizagem com recursos multimídia sobre o conteúdo identificado. Após a sua utilização pelos alunos, realizouse um processo de avaliação e os resultados obtidos indicam que a ferramenta contribui para o desenvolvimento e para a promoção de um maior interesse no assunto e maiores facilidades no processo de aprendizagem pelos alunos.

O texto segue com a seguinte organização: na seção 2 são descritas as principais teorias pedagógicas e sua associação com a EAD e breve discussão sobre a relação entre aprendizagem e interatividade e o uso de diferentes recursos digitais; na seção 3 é apresentado o desenvolvimento e resultados do estudo de caso. Por fim na seção 4 são feitas algumas considerações finais a respeito desta pesquisa.

\section{TEORIAS PEDAGÓGICAS, COMPETÊNCIAS DOCENTES E INTERATIVIDADE}

Há uma vasta literatura nacional e internacional sobre teorias pedagógicas fundamentais para apoio à EAD e se optou, neste artigo, por apresentar brevemente as três perspectivas dominantes de acordo com Filatro (2009) de forma a subsidiar as 
reflexões e a compreensão sobre o processo de ensino e aprendizagem nesta modalidade de ensino.

A perspectiva associacionista possui seus fundamentos em Pavlov, Watson e Thorndike sendo desenvolvida desde 1890 e considera a aprendizagem como uma mudança de comportamento. Após a Segunda Guerra Mundial, os autores passaram a pesquisar meios mais eficazes de planejar o ensino, influenciados pela taxonomia proposta por Bloom em meados de 1950, na medida em que foi criada uma linguagem comum e padronizada para identificar e classificar as atividades educacionais. A perspectiva associacionista preocupa-se, portanto, na aprendizagem ativa (o aprender fazendo), "com análise cuidadosa e feedback imediato de resultados e sobretudo alinhamento de objetivos de aprendizagem, estratégias instrucionais e métodos para avaliação" (FILATRO, 2009, p.97).

Em oposição ao associacionismo, a perspectiva cognitiva busca compreender os processos internos de percepção, representação, armazenamento e recuperação de conhecimentos, tendo sua origem na teoria de Piaget. Conforme afirma Filatro, "se as estruturas lógicas do pensamento são elaboradas ativamente pelo indivíduo, a aprendizagem não pode equivaler a uma recepção passiva do conhecimento" (2009, p.97). Quando novas informações são inseridas ao conhecimento, elas entram em conflito com o conhecimento prévio e isto impulsiona a busca de um novo equilíbrio e do desenvolvimento de novas estruturas mentais, o que Piaget chama de adaptação. Ausubel (1982) contribui com esta perspectiva afirmando que para que ocorra uma aprendizagem significativa em determinado espaço, como a sala de aula virtual, se faz necessário que os novos conhecimentos se relacionem com as ideias já existentes na estrutura cognitiva dos alunos, provenientes de suas experiências de vida. A aquisição do conhecimento torna-se o resultado de uma reflexão sobre a experiência o que permite a sua reconstrução e novos significados. Vygotsky, em meados de 1930, resgata a perspectiva socioconstrutivista onde a aprendizagem é o fator principal do desenvolvimento humano.

Relacionada com a perspectiva socioconstrutivista está a perspectiva da cognição situada que entende a aprendizagem como uma prática social, onde $o$ conhecimento está localizado na ação de pessoas e de grupos sendo distribuído socialmente. Nesta perspectiva, o contexto, a interação e a colaboração social são componentes fundamentais para a aprendizagem que acontece de forma dialogada, com o levantamento de vários pontos de vista que permitem aos alunos a aplicação de diferentes óticas para a solução de um problema. Como os indivíduos são influenciados pelo meio em que vivem - comunidade, cultura, entre outros - isto impacta, em certa medida, nos resultados de sua aprendizagem.

De posse da breve explicação destas três perspectivas pedagógicas da educação aplicadas a modalidade a distância, torna-se necessário a discussão sobre as competências inerentes aos docentes para a mediação digital e em rede. De acordo com Oliveira as competências profissionais podem ser definidas como o conjunto de conhecimentos, habilidades e atitudes que "capacitam um profissional a desempenhar as suas tarefas de forma satisfatória, tomando como critério avaliativo os padrões esperados em um determinado momento histórico, em uma determinada cultura" (2007, p. 76). Oliveira faz uso de três abordagens de competências docentes, provenientes de três autores da atualidade e relevantes no âmbito dos estudos sobre a docência e o trabalho dos professores tutores (ou professor não presencial).

A primeira abordagem teórica é a de Maurice Tardiff que entende que o saber (ou competência) do professor é plural por ser composto por diversas áreas do conhecimento, é estratégico pelo impacto que gera e também é desvalorizado, pois a 
sociedade não lhe atribui um papel tão importante como produtor de saberes. Em outras palavras, os saberes docentes são compreendidos por Tardiff como os saberes da formação profissional - transmitidos pelas instituições; os saberes disciplinares - das diversas áreas do conhecimento; os saberes curriculares - o conteúdo e o método que deve saber e, por fim, os saberes experienciais - desenvolvidos no exercício de sua função, ou seja, o "saber-fazer" e "saber-ser". A segunda abordagem de autoria de Antônio Nóvoa entende que as competências docentes se alicerçam na construção da identidade pela adesão a princípios e valores, pela autonomia de decisões e pela autoconsciência que permite a reflexão sobre a própria atuação. Tal identidade está em um processo constante de construção e transformação, pois é um lugar de lutas e conflitos que resultam em uma maneira de ser e estar na profissão de docente. A terceira abordagem que Oliveira cita em seu artigo é de autoria de Belloni que entende que o docente da modalidade EAD deve agir em parceria com os alunos no processo de construção do conhecimento e na inovação (ou renovação) da prática pedagógica. As competências inerentes aos docentes, sob a ótica de Belloni são: pedagógicas (orientação, aconselhamentos e tutoria), tecnológicas (produção, avaliação, seleção e definição de estratégias para o uso de materiais pedagógicos) e didáticas (formação específica do docente que deve ser sempre atualizada).

De acordo com as teorias de Piaget e Vygotsky é por meio das interações que os seres humanos aprendem e se desenvolvem. Mattar (2009) afirma que a interatividade na educação a distância pode se dar em diferentes níveis, conforme as atividades propostas nos cursos, que podem ser reativas - quando o aluno tem pouco controle sobre o conteúdo - ou ser proativas - quando o aluno tem maior controle sobre o conteúdo e até mesmo sobre a estrutura do curso. Há, basicamente, três tipos de interação que pode-se observar na EaD: aluno/professor, aluno/aluno e aluno/conteúdo. A interação entre aluno e professor pode ocorrer de forma síncrona ou assíncrona e é importante na medida em que introduz o conteúdo, motiva os alunos e ainda fornece o feedback, o que concretiza a interatividade.

A interação entre os alunos também pode ocorrer de forma síncrona ou assíncrona, resultando no aprendizado colaborativo e cooperativo, gerando motivação e atenção, pois os alunos aguardam o feedback dos colegas além de diminuir o isolamento do estudo a distância. Mattar (2009) afirma que com as TICs e a internet, ficou mais fácil para se criarem conteúdos e objetos de aprendizagem de forma que o aluno interaja de diversas maneiras, seja navegando, explorando, selecionando, controlando, construindo, respondendo e etc. e facilitando, assim, a interação entre aluno e conteúdo. Rigo (2010) afirma que os processos avançados de digitalização permitem aos usuários o acesso a livros, jornais, revistas e outros periódicos digitais e uma maior facilidade no compartilhamento de materiais de diferentes tipos de mídia, como vídeo, áudio, imagens e textos. Hoje se observa um processo de integração dos diversos formatos de mídia, gerando os conteúdos multimídia, aumentando as possibilidades de interação de alunos e professores nos ambientes virtuais de aprendizagem.

\section{ESTUDO DE CASO: DISCUSSÃO E RESULTADOS}

A escolha do assunto a ser tratado no estudo de caso deu-se a partir de reflexão sobre conteúdos com potencial ganho de aprendizagem, adicionando-se conteúdo mais atrativo que utiliza recursos digitais distintos e adequados às demandas observadas em situações práticas junto dos alunos. Verificou-se ao longo do ano de 2010, que o conteúdo de Elasticidade, gerava certa dificuldade de entendimento e, portanto, uma regular aquisição da competência esperada sobre este conteúdo. De forma resumida, 
este conteúdo denominado "Elasticidade" é estudado em disciplinas do curso de Administração de Empresas e de Contabilidade, sendo que trata de noções gerais da avaliação dos consumidores sobre aspectos do preço de produtos e permite avaliar numericamente estes comportamentos. $\mathrm{O}$ estudo de caso consiste na utilização do OA por um período de quatro bimestres, nos anos de 2011 e 2012, junto a treze turmas que totalizam setecentos alunos.

A criação de um objeto de aprendizagem é usualmente feita por uma equipe de profissionais da educação, autores com capacitação na área de conhecimento do OA e também uma equipe técnica composta por uma Designer Instrucional e por um desenhista e animador. Após a definição do conteúdo, foi elaborado um roteiro do objeto de aprendizagem que é o documento que norteia a construção da interface do mesmo. Nesta fase de construção, ainda pode-se fazer alterações ou modificações e após os ajustes finais foi validado o objeto de aprendizagem e posteriormente o mesmo foi disponibilizado no ambiente virtual de aprendizagem utilizado. Na semana de aula da atividade acadêmica na qual este assunto é tratado, foi disponibilizado juntamente com o material já existente, o objeto de aprendizagem desenvolvido, para os alunos que pudessem acessá-lo quantas vezes fosse necessário. A tela inicial do objeto de aprendizagem (OA) disponibilizado pode ser observada na figura 1 abaixo.
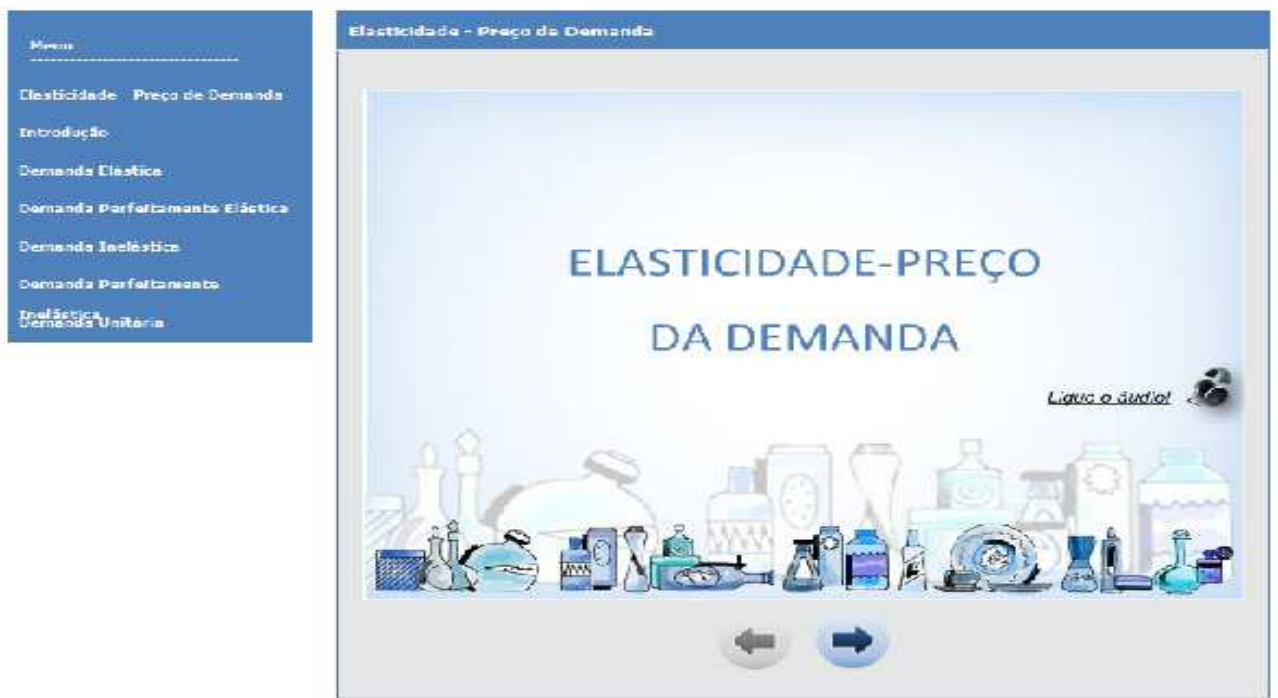

Figura 1 - Tela de abertura do objeto de aprendizagem

Os diferentes tipos de recursos selecionados para a construção deste material foram selecionados de forma conjunta entre os professores e a equipe de desenvolvimento, tendo como premissas a geração de facilidades para identificar situações cotidianas onde o conceito pode ser aplicado, o atendimento de alunos com diferentes perfis cognitivos, bem como a potencialização de experimentação dos conceitos de forma prática, tanto com base na interpretação numérica como na interpretação visual dos resultados. Assim foram empregadas animações, narração em áudio, textos de apoio, gráficos e apresentações de cálculos e de interpretações. No roteiro do OA foram abordados exemplos obtidos do cotidiano dos alunos que permitem a avaliação da alteração da demanda do consumidor pelo bem, motivadas por conta de uma variação nos preços. Isto foi apresentado na forma de uma animação envolvendo cenários reais e personagens fictícios gerados com desenho animado, tendo sido complementados com um roteiro narrado em áudio. A figura 2, abaixo, apresenta dois exemplos de cenários utilizados em diferentes pontos do objeto de aprendizagem para 
identificar exemplos de situações cotidianas onde os conceitos em estudo podem ser verificados.
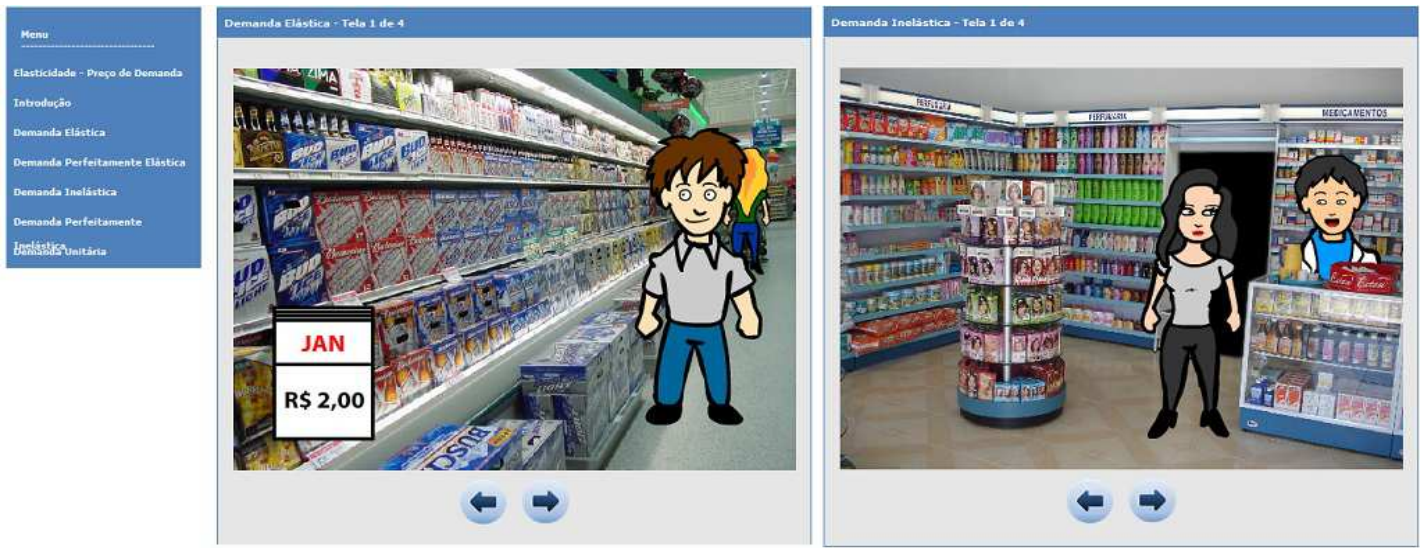

Figura 2 - Exemplos de cenários com personagens animados utilizados

Após a apresentação dos exemplos cotidianos, para os quais um dos objetivos era a criação de um laço mais claro entre teoria e prática, é exibido um conteúdo que permite avaliar numericamente o tipo de elasticidade em alguns exemplos de situações. Isto é realizado com o desenvolvimento detalhado dos cálculos necessários, sendo exibidos e comentados os resultados. Um dos objetivos desta abordagem é facilitar ao aluno o entendimento da aplicação das fórmulas de cálculo e o acompanhamento do processo de geração de resultados. Um exemplo destas situações pode ser visto na figura 3 abaixo.
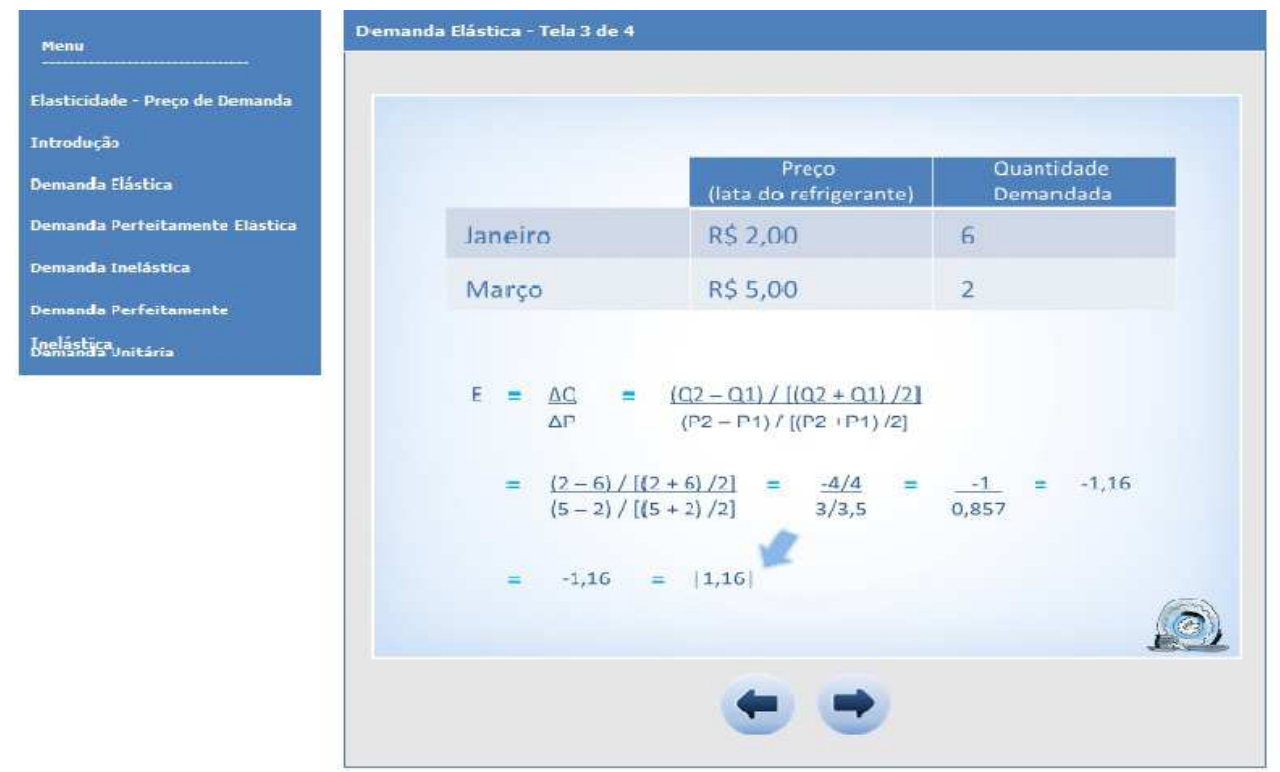

Figura 3 - Desenvolvimento do cálculo da elasticidade

Depois de exemplificado o cálculo, a proposta do roteiro para este objeto de aprendizagem foi de proporcionar ao aluno uma seção contendo comentários sobre o correto entendimento do tipo de demanda de cada exemplo, conforme sua elasticidade calculada, com utilização da análise gráfica. Assim foram apresentados e analisados gráficos animados e narrados para cada exemplo trabalhado, portanto usando texto, animação e áudio, como apresentado na figura 4. 


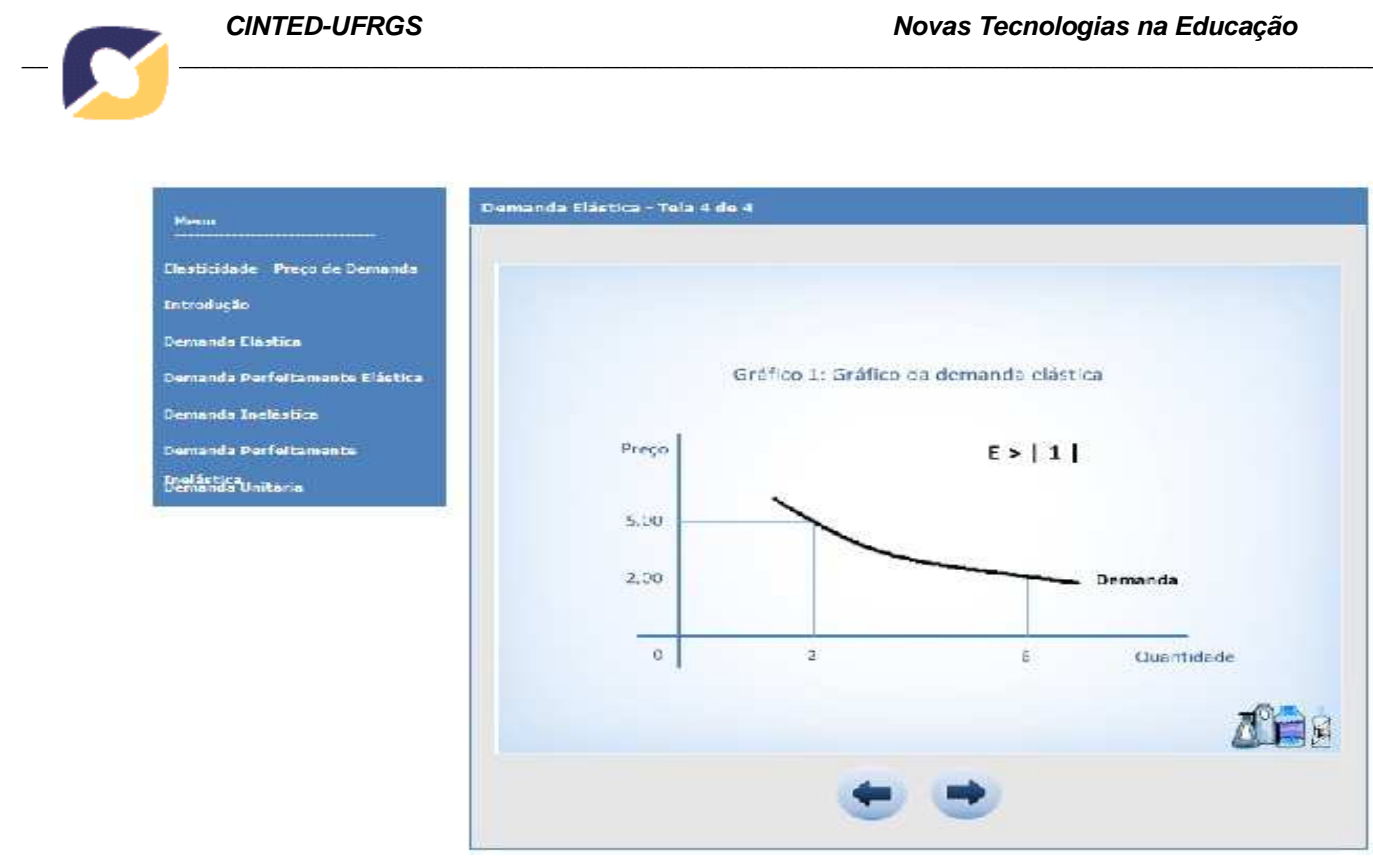

Figura 4 - Representação e análise gráfica

$\mathrm{Na}$ semana de aula seguinte ao uso do objeto de aprendizagem, foi disponibilizado aos alunos um questionário contendo perguntas que tem por objetivo avaliar o uso da ferramenta, ou seja, do objeto de aprendizagem. O questionário de avaliação foi elaborado com base em questionários de outros estudos como Pizzinato (2010), Magalhães (2010) e Gama (2007) e possui quatorze questões fechadas e uma questão aberta. Estas questões buscam identificar o perfil do aluno, as impressões sobre a usabilidade do OA e também o impacto dos conteúdos apresentados no OA para o aprendizado do aluno. Os resultados são apresentados a seguir.

$\mathrm{O}$ objeto de aprendizagem e a enquete de avaliação do mesmo foram disponibilizados em treze turmas da atividade acadêmica de Economia de Mercado, do primeiro semestre dos cursos de Administração e Ciências Contábeis, sendo que a motivação para o uso do OA e participação na avaliação foram realizadas da mesma forma, via mensagens de estímulo padronizadas postadas no fórum de notícias. O total da amostra, isto é, o total de matriculados nas turmas é de 700 alunos. Deste total 449 alunos responderam a enquete de avaliação do OA, o que corresponde a uma participação de $64 \%$ dos alunos.

De forma a montar um perfil dos alunos respondentes, algumas questões tratam da idade, gênero, perfil de uso do computador e acesso a internet. A grande maioria dos respondentes, 228 alunos ou 59\% da amostra, possuem entre 21 e 30 anos e na sequência os respondentes entre 31 e 40 anos somam 89 alunos ou ainda $23 \%$. Os respondentes até 20 anos e também acima de 40 anos foram 70 alunos, isto é, $18 \%$ da amostra em cada grupo. Constatou-se que $67 \%$ dos respondentes são do sexo feminino e $33 \%$ do sexo masculino. Com relação ao uso do computador para os mais variados fins observou-se que uma grande maioria, composta por $91 \%$ dos alunos, dizem utilizar o computador diariamente, enquanto que $7 \%$ afirmam utilizar o computador mais de 3 vezes por semana e somente $2 \%$ afirmam utilizar o computador menos de 3 vezes por semana. Os alunos foram questionados quanto ao tipo de acesso a internet que dispõem. Neste sentido observou-se que a grande maioria, 221 alunos ou 79\%, afirma ter acesso a internet em casa. Posteriormente os alunos foram questionados quanto a utilização da internet para os estudos especificamente, sendo que 137 alunos (60\%) responderam que utilizam a web diariamente para os estudos, 79 alunos (34\%) afirmaram que utilizam a web mais de 3 vezes por semana e somente 13 alunos (6\%) disseram que utilizam a web menos de 3 vezes por semana para os estudos. 
Após este bloco de questões que mostram um breve panorama sobre o perfil dos alunos respondentes da avaliação do $\mathrm{OA}$, as questões tratam especificamente do conteúdo do objeto de aprendizagem, sua apresentação, sua utilidade e relevância.

Os alunos foram questionados quanto ao seu conhecimento sobre o conteúdo tratado no objeto de aprendizagem antes de sua utilização, sendo que uma maioria de $47 \%$ apontou seu conhecimento como regular e $31 \%$ dos alunos afirmou que seu conhecimento sobre o conteúdo era bom. Já $12 \%$ entendem que o seu conhecimento era ruim antes do uso do objeto e $5 \%$ disseram que seu conhecimento era péssimo. Por fim, $4 \%$ indicaram que seu conhecimento sobre o conteúdo era muito bom antes da utilização do objeto. Outro questionamento procurou captar a percepção dos alunos quanto ao manuseio do objeto, questionando-os se ele é compreensível e de fácil utilização. A grande maioria, $67 \%$ dos alunos, respondeu que sim, sendo que $33 \%$ dos alunos entendeu que o mesmo atende parcialmente a este requisito. Observa-se ainda que nenhum aluno respondeu negativamente a esta questão. Questionou-se, também qual o grau de conhecimento sobre o conteúdo após a utilização do objeto de aprendizagem, sendo que $41 \%$ dos alunos indicaram que seu grau de conhecimento foi muito maior do que o que tinham antes do uso do objeto e $53 \%$ afirmaram que seu grau de conhecimento do conteúdo foi somente um pouco maior. Portanto um percentual de 94\% dos alunos considerou que seu conhecimento sobre o conteúdo foi maior ao de antes da utilização do objeto de aprendizagem. Os alunos foram questionados quanto a sua motivação para utilizar os objetos educacionais como auxílio na aprendizagem. Neste sentido, $50 \%$ dos alunos consideraram que sua motivação aumentou muito e $41 \%$ entendeu que aumentou um pouco, somando, portanto, $91 \%$ o número total de alunos que indicou aumento na motivação. Buscou-se compreender se o uso do objeto despertou o interesse sobre o conteúdo que ele tratou, sendo que $80 \%$ dos alunos afirmaram que sim e $20 \%$ alunos afirmaram que despertou parcialmente. Perguntou-se ainda se a animação com os gráficos auxiliaram na compreensão do conteúdo, sendo que $70 \%$ dos alunos entendeu que sim e $30 \%$ disseram que parcialmente. A última questão fechada perguntava ao aluno se ele usaria este tipo de objeto de aprendizagem novamente sendo que a grande maioria, $89 \%$ sinalizou que sim $11 \%$ dos alunos disseram que sim parcialmente.

A única questão aberta do questionário de avaliação tinha o objetivo de ser um espaço onde o aluno poderia tecer comentários quanto ao uso do objeto de aprendizagem. Cerca de $84 \%$ dos alunos responderam com importantes observações que evidenciam que a ferramenta utilizada proporcionou um melhor entendimento sobre o conteúdo, pois o objeto de aprendizagem estimula as diferentes funções cognitivas dos alunos, é interativo, motiva-os com uma ferramenta diferente das usuais disponíveis e ainda aproxima o conteúdo teórico da realidade, tendo em vista que foi utilizada uma linguagem clara e exemplos do cotidiano dos alunos. Outros comentários feitos pelos alunos mostram que o objeto poderia incluir mais exemplos, abrangendo o conteúdo de forma mais ampla e que poderia ser aplicado para diversos conteúdos e disciplinas. Alguns destes trechos com percepções dos alunos sobre o uso do AO são reproduzidos a seguir, com finalidade de exemplificação: "Adorei este novo método, pois foge dos textos, eu particularmente aprendo muito mais com histórias, figuras e exemplos práticos do dia-a-dia."; "Muito interessante, pois ele utiliza animações e situações do dia-a-dia, o que torna o entendimento muito mais fácil"; "Achei muito interessante, de fácil entendimento, prático, motivador".

Além do questionário acima descrito, cujo objetivo era obter a avaliação explícita dos alunos, os seguintes instrumentos foram utilizados para fins de análise do impacto deste OA: um questionário sobre conceitos de Elasticidade; um fórum de 
dúvidas sobre este assunto; materiais em texto e apresentações sobre os conceitos de Elasticidade. Considera-se que estes instrumentos permitem ampliar a avaliação dada pelo questionário de avaliação específica do OA, uma vez que permitem atestar os resultados obtidos pelos alunos neste conteúdo. Assim, observando-se as turmas em análise identifica-se uma melhoria nas médias comparadas dos alunos para o resultado do questionário nas turmas anteriores ao uso do objeto de aprendizagem. Além disso, observa-se também uma diminuição do número de mensagens no fórum de perguntas contendo dúvidas específicas sobre o assunto tratado no objeto de aprendizagem. Também se observa que todos os alunos de todas as turmas realizaram o acesso ao objeto de aprendizagem, bem como ao material textual sobre este assunto. A grande maioria dos alunos acessou mais de uma vez o objeto de aprendizagem, sendo constatada uma média de 4,6 acessos no geral.

\section{CONSIDERAÇÕES FINAIS}

Com relação aos resultados referentes ao objeto de aprendizagem, os dados apresentados indicam que os recursos digitais multimídia utilizados de forma conjunta no OA (texto, áudio, vídeo, imagens, animação) contribuíram para a motivação dos alunos, tendo sido constatado pelos questionários a percepção dos alunos de que o objeto se apresenta com uma interface amigável, interativa e de fácil navegação. Também foi possível avaliar que com o uso do OA houve um maior interesse pelo conteúdo abordado - sendo trabalhado com recursos que estimulam os diferentes perfis cognitivos - e ainda o aprimoramento do conhecimento, resultando em ganhos no processo de ensino e aprendizagem.

A avaliação do OA feita pelos alunos resultou em observações bastante positivas no que tange a motivação e interesse dos alunos pelo conteúdo, pela apresentação do OA e também pelo apoio na construção do conhecimento, o que indica ganhos em todo o processo de ensino e aprendizagem. Conforme afirma Mattar (2009, p. 118) "o grau das interações também varia em função das mídias utilizadas, como texto, áudio, vídeo, teleconferência, entre outras. A combinação planejada dessas diferentes formas de interação é um dos desafios da EAD". A análise do perfil geral dos alunos permite identificar que em sua grande maioria os estudantes utilizam muito frequentemente $o$ acesso a recursos digitais e, em especial, para fins de estudo, o que reforça a importância de utilização destes recursos, dado que são percebidos pelos alunos como elementos bastante integrados ao seu cotidiano.

A partir da relação entre aprendizagem e interatividade, das competências dos professores tutores, do modelo de ensino proposto pela instituição de ensino e do ambiente virtual de aprendizagem pode-se utilizar de diversas e variadas ferramentas tendo em vista a manutenção do diálogo e da interação com o aluno, além de motivá-lo para sua aprendizagem. O uso das tecnologias com diferentes possibilidades de interação é um dos desafios da EAD no século XXI que pode resultar no aprendizado de maior qualidade. Para tanto, acredita-se que seja fundamental a utilização de recursos de forma adequada e embasada em necessidades reais, fundamentados com a análise de equipes abarcando os diversos conhecimentos envolvidos. 


\section{REFERÊNCIAS BIBLIOGRÁFICAS}

AUSUBEL, D. P. A aprendizagem significativa: a teoria de David Ausubel. São Paulo: Moraes, 1982.

FILATRO, Andrea. As teorias pedagógicas fundamentais em EaD. In: LITTO, Fredric Michael; FORMIGA, Manuel Marcos Maciel (Orgs.). Educação a distância: o estado da arte. São Paulo: Pearson Education do Brasil, 2009. cap. 14, p. 96-103.

GAMA, Carmen Lúcia G. da. Método de Construção de Objetos de Aprendizagem com Aplicação em Métodos Numéricos. 2007. 210 f. Tese (Doutorado em Métodos Numéricos em Engenharia) - Programa de Pós-Graduação em Métodos Numéricos em Engenharia. Universidade Federal do Paraná, Curitiba, PR, 2007. Disponível em: < http://www.ppgmne.ufpr.br/arquivos/teses/9.pdf>. Acesso em: maio de 2012.

MAgalhães, Edson Macedo. Projeto R-PAM (Remote Personal Assistant for Moodle)- Assistente Pessoal Remoto para o Moodle. 2010. 179 f. Trabalho de Conclusão de Curso (Bacharel em Sistemas de Informação). Curso de Sistemas de Informação. Universidade do Vale do Rio dos Sinos, São Leopoldo, RS, 2010.

MATTAR, João. Interatividade e aprendizagem. In: LITTO, Fredric Michael; FORMIGA, Manuel Marcos Maciel (Orgs.). Educação a distância: o estado da arte. São Paulo: Pearson Education do Brasil, 2009. cap. 16, p. 112-120.

OLIVEIRA, Eloiza da Silva Gomes de. Ação Docente na educação a distância: competências para a mediação em rede. In: GARCÍA CARRASCO, Joaquin; SEOANE PARDO, Antón M. (Coord.). Tutoria virtual y e-moderación em red. Revista Electrónica Teoria de la Educación: Educación y Cultura em la Sociedad de la Información, ISSN 1138-9737, vol. 8, no. 2, 2007. P. 69-85. Disponível em: <http://campus.usal.es/ teoriaeducacion/rev_numero_08_02/n8_02_oliveira.pdf > .

Acesso em: maio de 2012.

PIZZINATO, Patrícia Mylius. Um Visualizador Online de Ontologias utilizando Árvores Hiperbólicas. 2010. 92 f. Trabalho de Conclusão de Curso (Bacharel em Ciência da Computação). Curso de Ciência da Computação. Universidade do Vale do Rio dos Sinos, São Leopoldo, RS, 2010.

RIGO, Sandro José. Introdução à educação a distância. São Leopoldo: Unisinos, 2010 .

VALENTE, J. A. A espiral da aprendizagem e as tecnologias da informação e comunicação: repensando conceitos. In: JOLY, M. C. R. A. A Tecnologia no Ensino: Implicações para a aprendizagem. São Paulo: Casa do Psicólogo, 2002.

WILEY, D. The instructional use of learning objects. On-line version. 2000. Disponível em: <http://reusability.org/read/> . Acesso em: maio de 2012. 